\title{
CHEMOSPHERE
}

Chemosphere 63 (2006) 751-761

www.elsevier.com/locate/chemosphere

\section{Model comparison for risk assessment: A case study of contaminated groundwater}

\author{
Yen-chuan Chen, Hwong-wen Ma * \\ Graduate Institute of Environmental Engineering, National Taiwan University, 71 Chou-Shan Road, Taipei 106, Taiwan
}

Received 7 October 2004; received in revised form 25 July 2005; accepted 9 August 2005

Available online 6 October 2005

\begin{abstract}
Many environmental multimedia risk assessment models have been developed and widely used along with increasing sophistication of the risk assessment method. Despite of the considerable improvement, uncertainty remains a primary threat to the credibility of and users' confidence in the model-based risk assessments. In particular, it has been indicated that scenario and model uncertainty may affect significantly the assessment outcome. Furthermore, the uncertainty resulting from choosing different models has been shown more important than that caused by parameter uncertainty. Based on the relationship between exposure pathways and estimated risk results, this study develops a screening procedure to compare the relative suitability between potential multimedia models, which would facilitate the reduction of uncertainty due to model selection. MEPAS, MMSOILS, and CalTOX models, combined with Monte Carlo simulation, are applied to a realistic groundwater-contaminated site to demonstrate the process. It is also shown that the identification of important parameters and exposure pathways, and implicitly, the subsequent design of uncertainty reduction and risk management measures, would be better-formed.
\end{abstract}

(c) 2005 Elsevier Ltd. All rights reserved.

Keywords: Uncertainty; Model uncertainty; Sensitivity; Multimedia models; Monte Carlo; Conceptual model

\section{Introduction}

In many countries, more and more sites with contaminated groundwater caused by improper handling or disposal of hazardous materials or wastes have been found. These sites may cause adverse effects on the environment and human health, and thus need to be evaluated as to whether and what remediation scheme should be applied. Health risk assessment is deemed as the most important tool for quantifying human health impact

\footnotetext{
* Corresponding author. Tel.: +88622363 0406; fax: +8862 23928830.

E-mail address: hwma@ntu.edu.tw (H.-w. Ma).
}

associated with pollutant-releasing activities and hence has become widely used as an aid in environmental decision-making processes (Maxwell and Kastenberg, 1999; Ma, 2002).

Health risk assessment involves identifying the potential of a risk source to introduce risk agents into the environment, estimating the amount of risk agents that come into contact with the human-environment boundaries, and quantifying the health consequence of exposure. Since the risk assessment paradigm was established in 1983 (NRC, 1983), the methodology of risk assessment has become more sophisticated. Compared to traditional generic, single-medium, and deterministic risk assessment methods, site-specific, multimedia, and stochastic risk assessment has become common practice. However, 
despite of the considerable improvement of the method, uncertainty remains a primary threat to the credibility of and hence users' confidence in the model-based risk assessments. Recent research on risk assessment has focused on uncertainty, because the uncertainty associated with parameter inaccuracy or variation, model simplification and inadequacy, and unsuited scenario designation often perplexes the users and decision makers in the process of risk assessment and management. Nevertheless, except research related to parameter uncertainty, the analysis of model and scenario uncertainty in the recent literature is still rare. Although the contribution of scenario and model uncertainty to overall uncertainty is usually assumed negligible or ignored, both types of uncertainty may affect significantly the outcome of risk assessment (Moschandreas and Karuchit, 2002). Some researches tried to quantify scenario and model uncertainty, and the outcome revealed that the total uncertainty including scenario, model and parameter uncertainty is three times greater than that considering only parameter uncertainty (Moschandreas and Karuchit, 2002). Although it has been indicated that scenario and model uncertainty are the important contributors to the total uncertainty, there are no practical measures as to how model and scenario uncertainty could be reduced.

Currently, many multimedia risk assessment models for implementing site-specific risk assessment have been developed, including MEPAS (Buck et al., 1995), MMSOILS (USEPA, 1996), CalTOX (Mckone, 1993a,b,c), 3MRA (USEPA, 2003), and TRIM (USEPA, 2002a,b), etc. One of these or related models will be adopted based on characteristics of different contaminated sites and scenario assumptions. But it is a difficult task for an inexperienced modelers to choose from so many environmental multimedia models (Del Re and Trevisan, 1995; Garen et al., 1999). Quite a few researches have performed model comparison to study the relationship between model differences and estimated results recently. Although model developers have tried hard to avoid uncertainty existing in the process of model construction, the differences in model design, environmental mechanism, mathematical formulations, and assumptions can result in difference of risk predictions by orders of magnitude (Laniak et al., 1997; Mills et al., 1997; Regens et al., 2002). Moreover, the uncertainty resulting from choosing different models has been shown more important than that caused by parameter uncertainty (Pollock et al., 2002). However, the finding that the results produced from different models may vary significantly does not provide suggestion as to which model is the best, except underlining the importance of understanding the limitations and assumptions of these multimedia models, and the compatibility between conceptual model and multimedia models to avoid the large errors introduced through use of impro- per models (Mills et al., 1997; Whelan et al., 1999; Regens et al., 2002).

Although model selection will cause considerable model uncertainty, very few studies explored the quantification and reduction of model uncertainty. Hertwich et al. (2000) even concluded that scenario and model uncertainty could be only exploratory and difficult to analyze quantitatively. At present the quantification of model uncertainty is generally conducted by way of calculating the range of outputs of different models (Moschandreas and Karuchit, 2002). Therefore, developing a screening procedure to compare the relative suitability between potential multimedia models would facilitate the reduction of uncertainty due to model selection by excluding unsuitable model. In other words, this study attempts to find out the relation between exposure pathways and estimated risk results and use this information to select the proper model through comparison of environmental multimedia models. A realistic groundwater contamination site is used as the case study.

\section{Materials and methods}

\subsection{The contaminated-groundwater problem and conceptual model development}

The important first step to implement risk assessment for a contaminated site is to develop the conceptual model of the site (Regens et al., 2002). The conceptual model is a descriptive model which uses available information to define all sources, types, and concentrations of contaminants, potentially contaminated media, potential exposure pathways, and final receptors (USEPA, 1989, 1991). According to the developed conceptual model, the exposure pathways in each multimedia model can be selected to correspond to the practical scenario.

The case study considered in this research is about a site, located in northern Taiwan, where it was discovered that the soil and groundwater was contaminated by chlorinated hydrocarbons, primarily trichloroethylene (TCE) and tetrachloroethylene (PCE). These chemicals were used as degreasing solvents by a local factory but improper handling and disposal of wasted solvents led to leakage and subsequent contamination of soil and groundwater.

Extensive resources and efforts have been spent in cleaning up the site. The soil cleanup has been considered complete, but little success has been reached for groundwater, due to dense-non-aqueous-phase-liquid's distinct physical characteristics that increase the difficulty of its identification and removal. At this point, the government needs to determine an appropriate course of management of groundwater contamination and subsequent feasibility of land use and development. 
Risk assessment has been called forth to evaluate the problem and to facilitate the decision-making.

Based on the land use property and spatial pattern of contaminant concentration, the site is divided into four zones, each of which is assessed individually. This paper uses a case of one of the four zones: $80000 \mathrm{~m}^{2}$ of farmland with scattered residences. According to the observations of 10 monitoring wells in this zone, the mean and standard error of the contaminant concentrations are 0.000741 and $0.000095 \mathrm{mg} \mathrm{l}^{-1}$ for TCE, respectively, and 0.000931 and $0.000285 \mathrm{mg} \mathrm{l}^{-1}$ for PCE, respectively (Taiwan EPA, 2003). The soil is deemed free of contamination according to the site investigation, and the contamination source in this case study is the groundwater, which the residents use for domestic purposes and irrigation. The contaminated media includes domestic water, indoor air, irrigation soil, vegetables, crops, and farm animals. The exposure pathways include ingestion of drinking water, ingestion of shower water, ingestion of beef, ingestion of milk, ingestion of vegetables, ingestion of crop, ingestion of soil, dermal contact of soil, dermal contact of shower water, inhalation of shower air, and inhalation of indoor air. Fig. 1 depicts the conceptual site model that illustrates the environmental transfer processes between media and exposure pathways linking exposure media and exposure routes involved in this specified scenario.

\subsection{Multimedia risk assessment models}

Many multimedia risk assessment models have been developed for performing site-specific risk assessment. For the purpose of demonstration, MEPAS, MMSOILS, and CalTOX are chosen for model comparison because these models are widely used environmental multimedia models and suitable for groundwater-contaminated site assessment.
The scenario included in this case study is that the residents use groundwater for irrigation and domestic purposes. In this scenario, comparing each multimedia model with the conceptual model can find that MEPAS model has the most complete exposure pathways, including the 11 exposure pathways stated in Section 2.1. MMSOILS excludes three exposure pathways: ingestion of shower water, inhalation of shower air, and inhalation of indoor air, while CalTOX does not consider pathways of shower water ingestion, soil ingestion and dermal contact of soil. All the three models follow the same principle to calculate exposure dose and human risk, which can be described by the following equation (USEPA, 1989):

$$
\begin{aligned}
\text { CancerRisk } & =\sum_{k}\left[1-\exp \left(\mathrm{ADI}_{k} \times \mathrm{CSF}_{k}\right)\right] \\
& \approx \sum_{k} \mathrm{ADI}_{k} \times \mathrm{CSF}_{k}
\end{aligned}
$$

where $\mathrm{ADI}_{k}$ is the average daily intake $\left(\mathrm{mg} \mathrm{kg}^{-1} \mathrm{day}^{-1}\right)$ of the contaminants by receptors through exposure route $k$ (inhalation, ingestion, or dermal absorption), $\mathrm{CSF}_{k}$ is the cancer slope factor $\left(\mathrm{kg}\right.$ day $\left.\mathrm{mg}^{-1}\right)$ of exposure route $k$, which is derived from dose-response studies.

In practice, the linearized portion is used for small value of $\mathrm{ADI} \times \mathrm{CSF}$. ADI is the amount of contaminants received by human bodies via all exposure pathways, and is evaluated based on the following equation (Mckone, 1993a):

$$
\mathrm{ADI}_{i j k}=C_{i} \times\left[\frac{C_{j}}{C_{i}}\right] \times\left[\frac{\mathrm{CR}_{i j k}}{\mathrm{BW}}\right] \times \frac{\mathrm{EF} \times \mathrm{ED}}{\mathrm{AT}}
$$

where $\mathrm{ADI}_{i j k}\left(\mathrm{mg} \mathrm{kg}^{-1} \mathrm{day}^{-1}\right)$ is the average daily intake from environmental media $i$ (air, soil or groundwater), exposure media $j$ (drinking water, food, etc.) and exposure route $k$ (inhalation, ingestion, or dermal

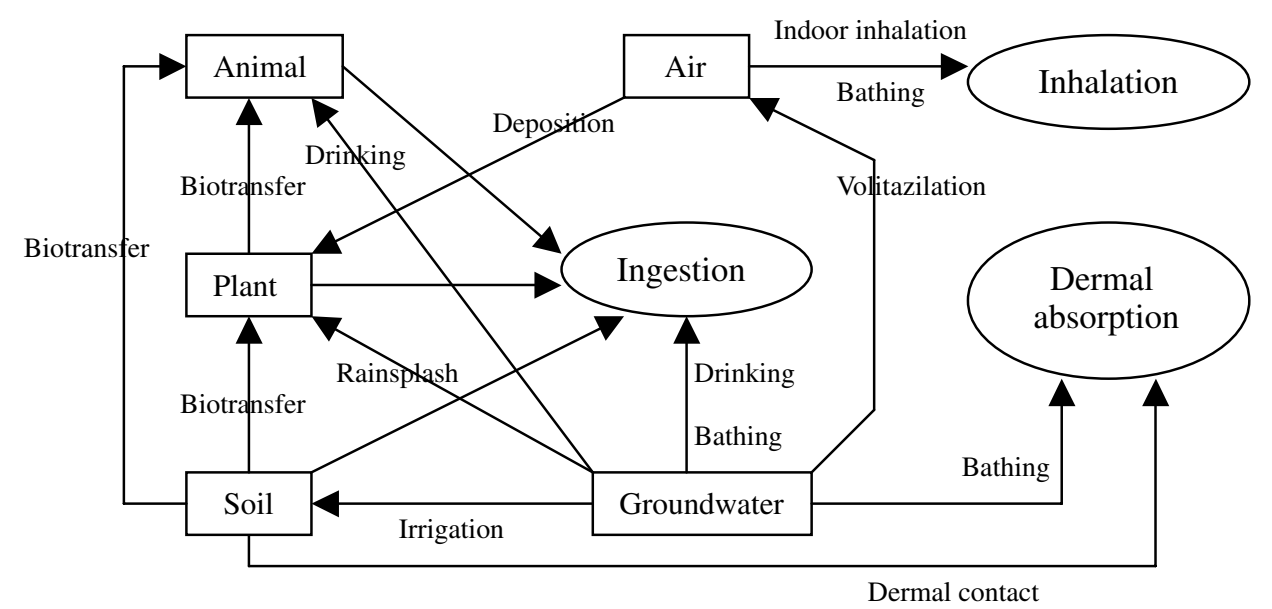

Fig. 1. The multimedia transfer processes and multiple exposure pathways associated with a contaminated-groundwater scenario. 
absorption), $C_{i}$ is the pollution concentration in environmental media $i, C_{j}$ is the pollution concentration in exposure media $j, \mathrm{CR}_{j k}$ is the contact rate of exposure media $j$ through exposure route $k, \mathrm{EF}$ is the exposure frequency, ED is the exposure duration, AT is the averaging time, and BW is the body weights of receptors.

The pollution concentration in exposure media, $C_{j}$, calculated from the different mathematical formulations in different multimedia models will produce different risk outcomes, and the outcomes can be the basis for choosing better models.

\subsection{Uncertainty analysis and identification of important information}

To reflect the uncertainty of risk estimates associated with parameters, a Monte Carlo technique is used to propagate parameter uncertainty. Each of the input parameters that are considered uncertain is treated as a random variable with known or estimated probability density function (pdf). For each of the variables, one value is selected at random with respect to the associated pdf. The individual cancer risk is then calculated by using environmental multimedia risk assessment models with any sample set of input values. The sampling and calculation are repeated 5000 times, which has been examined sufficient to avoid unacceptable variance in different realizations, to produce the pdf of the risk estimate in this case study. In this case consideration, there are 55, 43, and 33 parameters in MEPAS, CalTOX, and MMSOILS, respectively. 33, 28, and 24 parameters, in order of the above, are treated stochastically.

Along with the Monte Carlo simulation, sensitivity analysis method is used to identify important information, whose uncertainty is a driving factor in the overall uncertainty of risk estimates for population. In this study, a rank correlation coefficient between each input parameter and the associated risk output is computed to measure the importance of each parameter to the overall uncertainty. The rank correlation coefficients are indicators of the degree of monotonic relationship between the sample values of the model prediction and those of the uncertain inputs. For this reason, rank correlation coefficients often work better to rank parameter contributions to uncertainty than other methods that are based on linear relationship only (Ma, 2002).

The following provides the procedures of screening models to reduce uncertainty due to improper model selection. Identification of important parameters with great contribution to uncertainty of risk estimates is also included to facilitate planning of information collection efforts for reducing parameter uncertainty.

(1) According to the contamination and site characteristics and exposure scenarios assumed in the practical situation, develop the conceptual site model to incorporate the relevant exposure pathways in these environmental multimedia models.

Table 1

The risk values at 95th percentile for specified pathways in the multimedia models and the differences of the modeling results

\begin{tabular}{|c|c|c|c|c|c|c|c|c|}
\hline \multirow[t]{3}{*}{ Exposure pathway } & \multicolumn{6}{|c|}{ Multimedia models } & \multirow{2}{*}{\multicolumn{2}{|c|}{$\begin{array}{l}\text { The difference among } \\
\text { models }\end{array}$}} \\
\hline & \multicolumn{2}{|l|}{ MEPAS } & \multicolumn{2}{|l|}{ MMSOILS } & \multicolumn{2}{|l|}{ CalTOX } & & \\
\hline & Risk & $\begin{array}{l}\text { Contribution } \\
(\%)\end{array}$ & Risk & $\begin{array}{l}\text { Contribution } \\
(\%)\end{array}$ & Risk & $\begin{array}{l}\text { Contribution } \\
(\%)\end{array}$ & $\begin{array}{l}\text { Absolute } \\
\text { difference }^{\mathrm{a}}\end{array}$ & $\begin{array}{l}\text { Relative } \\
\text { difference }^{b}\end{array}$ \\
\hline $\begin{array}{l}\text { Ingestion of } \\
\text { drinking water }\end{array}$ & $1.06 \mathrm{E}-06$ & 27.35 & $1.09 \mathrm{E}-06$ & 83.78 & $1.08 \mathrm{E}-06$ & 48.24 & $3.00 \mathrm{E}-08$ & 0.0116 \\
\hline $\begin{array}{l}\text { Ingestion of } \\
\text { shower water }\end{array}$ & $6.08 \mathrm{E}-09$ & 0.16 & - & - & - & - & $6.08 \mathrm{E}-09$ & 0.0024 \\
\hline Ingestion of meat & $8.76 \mathrm{E}-12$ & 0.00 & $8.63 \mathrm{E}-12$ & 0.00 & $7.25 \mathrm{E}-12$ & 0.00 & $1.51 \mathrm{E}-12$ & 0.0000 \\
\hline Ingestion of milk & $6.59 \mathrm{E}-12$ & 0.00 & $6.81 \mathrm{E}-12$ & 0.00 & $5.65 \mathrm{E}-12$ & 0.00 & $1.16 \mathrm{E}-12$ & 0.0000 \\
\hline Ingestion of vegetables & $1.12 \mathrm{E}-07$ & 2.89 & $2.69 \mathrm{E}-08$ & 2.07 & $4.97 \mathrm{E}-08$ & 2.22 & $8.51 \mathrm{E}-08$ & 0.0330 \\
\hline Ingestion of crop & $2.21 \mathrm{E}-07$ & 5.70 & $9.73 \mathrm{E}-08$ & 7.48 & $9.56 \mathrm{E}-08$ & 4.27 & $1.25 \mathrm{E}-07$ & 0.0484 \\
\hline Ingestion of soil & $2.96 \mathrm{E}-11$ & 0.00 & $3.89 \mathrm{E}-14$ & 0.00 & - & - & $2.96 \mathrm{E}-11$ & 0.0000 \\
\hline $\begin{array}{l}\text { Dermal contact of } \\
\text { shower }\end{array}$ & $4.19 \mathrm{E}-08$ & 1.08 & $8.51 \mathrm{E}-08$ & 6.55 & $8.23 \mathrm{E}-08$ & 3.68 & $4.32 \mathrm{E}-08$ & 0.0167 \\
\hline Dermal contact of soil & $1.54 \mathrm{E}-09$ & 0.03 & $1.76 \mathrm{E}-09$ & 0.14 & - & - & $1.76 \mathrm{E}-09$ & 0.0007 \\
\hline $\begin{array}{l}\text { Inhalation of } \\
\text { indoor air }\end{array}$ & $9.13 \mathrm{E}-07$ & 23.56 & - & - & $9.81 \mathrm{E}-08$ & 4.38 & $9.13 \mathrm{E}-07$ & 0.3539 \\
\hline $\begin{array}{c}\text { Inhalation of } \\
\text { shower air }\end{array}$ & $1.52 \mathrm{E}-06$ & 39.22 & - & - & $8.33 \mathrm{E}-07$ & 37.21 & $1.52 \mathrm{E}-06$ & 0.5891 \\
\hline Total risk & $3.88 \mathrm{E}-06$ & 100 & $1.30 \mathrm{E}-06$ & 100 & $2.24 \mathrm{E}-06$ & 100 & $2.58 \mathrm{E}-06$ & - \\
\hline
\end{tabular}

${ }^{a}$ The absolute difference is the value of difference between the estimated largest and smallest risks in each exposure pathway.

b The relative difference is the value of the absolute difference in each exposure pathway divided by the absolute difference of total risk. 
For each multimedia model and considered exposure pathway, perform risk calculations and uncertainty analysis of parameters described above to produce probability distribution of risk estimates.

(2) Determine an appropriate percentile (e.g., 95th percentile) from the cumulative probability distributions produced in step (1). The value corresponding to the pre-determined percentile and individual exposure pathways for each model are compared and the important exposure pathways with great risk contributions are identified.

(3) The differences of the total risk values estimated by various models are used to represent model uncertainty. The relative differences of individual exposure pathway (see Table 1) among the models are also calculated to illuminate the relative magnitude of individual exposure pathway's divergence among the models. For the pathways with large divergence, the different algorithms in each model should be analyzed in order to understand the sources of model uncertainty. Further, when a model neglects an important exposure pathway, it is considered unsuitable for the case.

(4) Perform the sensitivity analysis described in Section 2.3 for the models that are not screened out in step (3) to determine the important parameters.

\section{Results and discussion}

\subsection{The differences of the risk among the multimedia models in the specific scenario}

The risk values at the 95th percentile for each exposure pathway and each environmental multimedia model, and the differences between the modeling outputs are shown in Table 1.

In this case, it is found that inhalation of shower air, ingestion of drinking water, and inhalation of indoor air are the major contributors to the total health risk $(39.2 \%, 27.4 \%$, and $23.6 \%$ of the total risk, respectively) in the MEPAS model. Similarly, the most important pathways identified by CalTOX model are ingestion of drinking water, inhalation of shower air, and inhalation of indoor air $(48.2 \%, 37.2 \%$, and $4.4 \%$ of the total risk, respectively). However, the ranks of pathways are not identical for the two models, which is due to the different mathematical formulations and will be explained later in Section 3.2.

The simulation outcome of MMSOILS model is quite different from the other two models. It is found that ingestion of drinking water $(83.8 \%$ of the total risk) is the most dominant exposure pathway. The secondly and thirdly important pathways are ingestion of crop $(7.5 \%$ of the total risk) and dermal contact of shower (6.6\% of the total risk). The results of Table 1 suggest that different models will indeed produce different important pathways and estimated risk outcomes, although they are assessing the same case. From the comparison of the contribution of different exposure pathways, it can be seen that the obvious diversity among the three models results from the omission of the exposure pathways of the inhalation of shower air and inhalation of indoor air in the MMSOILS model.

\subsection{The analysis of model differences}

From the perspective of the total risk, the risk outputs of the three models range within the same order of magnitude and the model uncertainty computed based on the comparison of the three modeling outputs is $2.58 \times 10^{-6}$. However, in order for the risk results to be useful for understanding the sources of model uncertainty and designing risk management measures, the relative importance of various exposure pathways needs to be identified.

From the aspect of comparing risk results of various pathways, the differences of the risk results for inhalation of shower air, inhalation of indoor, ingestion of crop, and ingestion of vegetables (the values of relative difference are $0.5891,0.3539,0.0484$, and 0.0330 , respectively) accounted for the large part of the differences of the total risk between models, as presented in Table 1. These exposure pathways are included in two submodels: irrigation and indoor air. The following presents the differences in calculating plant concentrations due to irrigation and indoor air concentrations of the three models. Analyzing the algorithms of these pathways in the three models could identify the sources of model uncertainty and help to choose the better multimedia models.

\subsubsection{The differences in irrigation models for transferring contaminants from irrigation water to plant}

Calculation of contaminants transferred from irrigation water to plant in the MEPAS model includes two processes. One is the accumulation of the contaminants in soil, and the subsequent uptake by roots from soil to edible portion of plants; the other is the direct deposition of the contaminants from irrigation water onto plant surfaces, and subsequent transfer to edible portion of plants. The accumulation of pollutants in soil over multiple years is accounted for by a soil accumulation factor (SAF). The soil accumulation factor is evaluated as the time integral of the solution to the deposition and decay differential equation, normalized to unit deposition and averaged over the deposition period 
(Buck et al., 1995). The calculations are represented by Eqs. (1) and (2) in Table 2. The explanations of notation in Table 2 are attached as Appendix A. After calculating $\mathrm{SAF}$, the plant contamination $\left(C_{\mathrm{lvi}}\right)$ resulting from irrigation deposition onto edible parts of plants and root uptake from soil is estimated through Eqs. (3) and (4) in Table 2.

Compared to MEPAS model, MMSOILS model does not consider the deposition of contaminants from irrigation water to plant surfaces. Instead, it only calculates the deposition of contaminants from irrigation water to soil and the subsequent uptake of contaminants by plant roots. The influence of recharge, soil erosion, and chemical degradation has been included in the calculation of soil concentration from irrigation water (USEPA, 1996). The leafy vegetable plant concentration $\left(C_{\mathrm{vu}}\right)$ is estimated from Eq. (5) in Table 2.

CalTOX model simulates chemical concentration of exposed produce sprayed with irrigation water and up- take through root directly, without calculating the soil concentration, which is the inter-medium in the transfer pathway (Mckone, 1993c). Therefore, in contrast to MEPAS and MMSOILS models, CalTOX model does not consider ingestion of soil and dermal contact of soil, although both pathways are explicitly addressed in CalTOX model. The chemical concentration of exposed produce is calculated by Eq. (6) in Table 2.

\subsubsection{The differences in indoor air models}

Two submodels are included in the MEPAS model for calculating the risk from indoor inhalation of volatile pollutants: the MEPAS shower inhalation model and the USEPA Andelman indoor inhalation model. Although the concentration in shower air can be estimated by using Henry's law constant, the maximum allowable Henry's law constant is restricted to $2.4 \times$ $10^{-3} \mathrm{~m}^{3} \mathrm{~atm} \mathrm{~g}^{-1} \mathrm{~mol}^{-1}$ due to limitation of mass balance. Because both of Henry's law constant of TCE

Table 2

The differences of the mathematical formulations in MEPAS, MMSOILS, and CalTOX models

\begin{tabular}{|c|c|c|c|}
\hline Submodel & Model & \multicolumn{2}{|l|}{ Mathematical equations } \\
\hline \multirow[t]{5}{*}{$\begin{array}{l}\text { Irrigation model } \\
\text { from irrigation } \\
\text { water to plant }\end{array}$} & MEPAS & \multicolumn{2}{|c|}{ (1) $\frac{\mathrm{d} C_{\mathrm{awi}}}{\mathrm{d} t}=U D_{\mathrm{wi}}-C_{\mathrm{awi}} \lambda_{\mathrm{di}}, \quad$ and $\quad(2) \mathrm{SAF}_{i}=\frac{\int_{0}^{\mathrm{ED}_{\mathrm{KK}} 365.25} C_{\mathrm{awi}} \mathrm{d} t}{U D_{\mathrm{wi}} \mathrm{ED}_{\mathrm{KK}} 365.25}$} \\
\hline & & \multicolumn{2}{|c|}{ (3) $\begin{aligned} C_{\mathrm{lvi}} & =\left(\mathrm{CWD}_{\mathrm{lvi}}+\mathrm{CWR}_{\mathrm{lvi}}\right) \mathrm{e}^{-\lambda_{\mathrm{gi}} \mathrm{TH}_{\mathrm{lv}}} \\
& =\left[\mathrm{DP}_{\mathrm{wi}} \mathrm{TV}_{\mathrm{lv}} r_{\mathrm{lv}} \frac{\left(1-\mathrm{e}^{-\lambda_{\mathrm{ei}} \mathrm{TC}_{\mathrm{lv}}}\right)}{\lambda_{\mathrm{ei}} Y_{\mathrm{lv}}}+\frac{\mathrm{FI}_{\mathrm{lv}} \mathrm{SAF}_{i} B_{\mathrm{vi}} \mathrm{DP}_{\mathrm{wi}}}{P}\right] \mathrm{e}^{-\lambda_{\mathrm{gi}} \mathrm{TH}_{\mathrm{lv}}}\end{aligned}$} \\
\hline & & \multicolumn{2}{|l|}{ and (4) $\mathrm{DP}_{\mathrm{wi}}=\frac{C_{\mathrm{iri}} \mathrm{IR}}{30}$} \\
\hline & MMSOILS & \multicolumn{2}{|l|}{ (5) $C_{\mathrm{vu}}=B_{\mathrm{v}} f_{\mathrm{dw}} C_{\mathrm{as}}=B_{\mathrm{v}} f_{\mathrm{dw}} \frac{C_{\mathrm{irr}} D_{\mathrm{irr}} \mathrm{XF} 6}{\rho_{\mathrm{b}} D_{\mathrm{m}} \lambda_{\mathrm{s}}}$} \\
\hline & CalTOX & \multicolumn{2}{|c|}{ (6) $C_{\mathrm{fvg}}^{\mathrm{abgw}}=C_{\mathrm{q}} \mathrm{TF}(\mathrm{q} \rightarrow \mathrm{ep})=C_{\mathrm{q}} f_{\mathrm{q}}^{\mathrm{w}}\left(K_{\mathrm{ps}}^{\mathrm{rain}}+K_{\mathrm{ps}}\right) K_{\mathrm{D}} f_{\mathrm{ir}}$} \\
\hline \multirow[t]{7}{*}{ Indoor air model } & MEPAS & \multicolumn{2}{|c|}{ (7) Showering $\quad C_{\text {sai }}=10^{3} C_{\mathrm{dwi}} \mathrm{TF}_{i} \mathrm{e}^{-\lambda_{\mathrm{gi}} \mathrm{TH}_{\mathrm{dw}}}\left(\frac{H_{i}}{R T}\right)$} \\
\hline & & \multicolumn{2}{|l|}{ (8) Indoor $C_{\mathrm{iai}}=C_{\mathrm{dwi}} \mathrm{TF}_{i} \mathrm{e}^{\left(-\lambda_{\mathrm{gi}} \mathrm{TH}_{\mathrm{dw}}\right)} K_{\mathrm{c}}$} \\
\hline & MMSOILS & \multirow{2}{*}{\multicolumn{2}{|c|}{$\begin{array}{l}\text { No consideration } \\
\text { (9) Showering } C_{\text {ba }}=C_{\mathrm{q}} \mathrm{TF}(\mathrm{q} \rightarrow \text { bathair })=C_{\mathrm{q}} f_{\mathrm{q}}^{\mathrm{w}} \frac{W_{\text {bath }}}{\mathrm{VR}_{\text {bath }}} \phi_{x}(\text { bath })\end{array}$}} \\
\hline & CalTOX & & \\
\hline & & \multicolumn{2}{|c|}{$=C_{\mathrm{q}} f_{\mathrm{q}}^{\mathrm{w}} \frac{W_{\text {bath }}}{\mathrm{VR}_{\text {bath }}} \frac{1.8 \times 10^{5}}{\left[\frac{2.5}{D_{1}^{2 / 3}}+\frac{R T}{H \cdot D_{\mathrm{a}}^{2 / 3}}\right]}$} \\
\hline & & \multicolumn{2}{|c|}{ (10) Indoor $C_{\mathrm{ia}}=C_{\mathrm{q}} \mathrm{TF}(\mathrm{q} \rightarrow$ inair $)=C_{\mathrm{q}} f_{\mathrm{q}}^{\mathrm{w}} \frac{W_{\text {house }}}{\mathrm{VR}_{\text {house }}} \phi_{x}($ house $)$} \\
\hline & & $=C_{\mathrm{q}} f_{\mathrm{q}}^{\mathrm{w}} \frac{W_{\text {house }}}{\mathrm{VR}_{\text {house }}}$ & $\frac{2.1 \times 10^{5}}{\left.\frac{2.5}{D_{1}^{2 / 3}}+\frac{R T}{H \cdot D_{\mathrm{a}}^{2 / 3}}\right]}$ \\
\hline
\end{tabular}


and PCE in this case study are greater than $2.4 \times$ $10^{-3} \mathrm{~m}^{3} \mathrm{~atm} \mathrm{~g}^{-1} \mathrm{~mol}^{-1}$, this restricted value has been adopted. The shower air concentration is calculated by Eq. (7) in Table 2 (Lyman et al., 1982). For calculating the concentration in indoor air from domestic water, the following conditions must be met: Henry's law constant is greater than $10^{-5} \mathrm{~m}^{3} \mathrm{~atm} \mathrm{~g}^{-1} \mathrm{~mol}^{-1}$ and molecular weight is smaller than $200 \mathrm{~g}^{-1} \mathrm{~mol}$. The chemical concentration in the air in the home is evaluated as Eq. (8) in Table 2 (Andelman, 1990).

Because the atmospheric pathway in the MMSOILS model only considers the release of contaminants from the site in the form of vapors and fugitive dust emissions from wind erosion and mechanical disturbances, both of the important pathways, inhalation of shower air and inhalation of indoor air due to contaminants vaporizing from domestic water, are not evaluated. This is the essential reason that MMSOILS model deviates from the other two models in the case.

Although the calculation of indoor inhalation in the CalTOX model includes the same pathways as MEPAS, their mathematical formulations of the pathways are not the same. The formulations in the CalTOX are taken from Mckone and Bogen (1992) and are represented by Eqs. (9) and (10) in Table 2.

From the proceeding description of the formulations, the transfer pathways and mathematical equations of the three models related to contaminants from domestic water to indoor air and bathroom air are all different. The MMSOILS model even completely omits the indoor air model. It is apparent that the modeling divergence of pathways related to irrigation and indoor inhalation leads to the differences of the estimated risk results.

Therefore, before performing a risk assessment, the model uncertainty should be evaluated by first focusing on the relation between conceptual model and multimedia models, and on the significance of the neglected pathways and differences of mathematical formulations between multimedia models.

\subsection{The selection of the better models through model comparison and reduction of model uncertainty}

The relative importance of neglected pathways in the three models can be obtained from the value of relative difference in Table 1. While the MEPAS model has incorporated the 11 exposure pathways in the conceptual model, CalTOX model omits three pathways, including ingestion of shower water, ingestion of soil, and dermal contact of soil, which are shown not relatively significant, because their values of relative difference are 0.0024, 0.0000, and 0.0007, respectively. MMSOILS model eliminates the pathways of ingestion of shower water, inhalation of indoor air, and inhalation of shower air. Based on the values of relative difference shown in Table $1(0.0024,0.3539$, and 0.5891,

Table 3

The risk values for specified pathways and the differences of the modeling results without Monte Carlo simulation

\begin{tabular}{|c|c|c|c|c|c|c|c|c|}
\hline \multirow[t]{3}{*}{ Exposure pathway } & \multicolumn{6}{|c|}{ Multimedia models } & \multirow{2}{*}{\multicolumn{2}{|c|}{$\begin{array}{l}\text { The difference } \\
\text { among models }\end{array}$}} \\
\hline & \multicolumn{2}{|l|}{ MEPAS } & \multicolumn{2}{|c|}{ MMSOILS } & \multicolumn{2}{|l|}{ CalTOX } & & \\
\hline & Risk & $\begin{array}{l}\text { Contribution } \\
(\%)\end{array}$ & Risk & $\begin{array}{l}\text { Contribution } \\
(\%)\end{array}$ & Risk & $\begin{array}{l}\text { Contribution } \\
(\%)\end{array}$ & $\begin{array}{l}\text { Absolute } \\
\text { difference }^{\mathrm{a}}\end{array}$ & $\begin{array}{l}\text { Relative } \\
\text { difference }^{\mathrm{b}}\end{array}$ \\
\hline $\begin{array}{l}\text { Ingestion of } \\
\text { drinking water }\end{array}$ & $3.96 \mathrm{E}-07$ & 28.68 & $3.95 \mathrm{E}-07$ & 91.05 & $4.01 \mathrm{E}-07$ & 50.33 & $4.00 \mathrm{E}-09$ & 0.0042 \\
\hline $\begin{array}{l}\text { Ingestion of } \\
\text { shower water }\end{array}$ & $1.99 \mathrm{E}-09$ & 0.14 & - & - & - & - & $1.99 \mathrm{E}-09$ & 0.0021 \\
\hline Ingestion of meat & $2.39 \mathrm{E}-12$ & 0.00 & $2.40 \mathrm{E}-12$ & 0.00 & $2.60 \mathrm{E}-12$ & 0.00 & $2.10 \mathrm{E}-13$ & 0.0000 \\
\hline Ingestion of milk & $1.91 \mathrm{E}-12$ & 0.00 & $1.93 \mathrm{E}-12$ & 0.00 & $2.08 \mathrm{E}-12$ & 0.00 & $1.70 \mathrm{E}-13$ & 0.0000 \\
\hline $\begin{array}{l}\text { Ingestion of } \\
\text { vegetables }\end{array}$ & $1.38 \mathrm{E}-08$ & 1.00 & $2.51 \mathrm{E}-09$ & 0.58 & $1.52 \mathrm{E}-08$ & 1.91 & $1.27 \mathrm{E}-08$ & 0.0134 \\
\hline Ingestion of crop & $2.43 \mathrm{E}-08$ & 1.76 & $9.83 \mathrm{E}-09$ & 2.27 & $2.96 \mathrm{E}-08$ & 3.72 & $1.98 \mathrm{E}-08$ & 0.0209 \\
\hline Ingestion of soil & $3.61 \mathrm{E}-12$ & 0.00 & $3.92 \mathrm{E}-15$ & 0.00 & - & - & $3.61 \mathrm{E}-12$ & 0.0000 \\
\hline $\begin{array}{l}\text { Dermal contact of } \\
\text { shower }\end{array}$ & $1.53 \mathrm{E}-08$ & 1.10 & $2.63 \mathrm{E}-08$ & 6.06 & $2.62 \mathrm{E}-08$ & 3.29 & $1.10 \mathrm{E}-08$ & 0.0116 \\
\hline Dermal contact of soil & $1.80 \mathrm{E}-10$ & 0.01 & $1.95 \mathrm{E}-10$ & 0.04 & - & - & $1.95 \mathrm{E}-10$ & 0.0002 \\
\hline $\begin{array}{l}\text { Inhalation of } \\
\text { indoor air }\end{array}$ & $3.93 \mathrm{E}-07$ & 28.45 & - & - & $4.07 \mathrm{E}-08$ & 5.11 & $3.93 \mathrm{E}-07$ & 0.4145 \\
\hline $\begin{array}{c}\text { Inhalation of } \\
\text { shower air }\end{array}$ & $5.37 \mathrm{E}-07$ & 38.85 & - & - & $2.84 \mathrm{E}-07$ & 35.65 & $5.37 \mathrm{E}-07$ & 0.5677 \\
\hline Total risk & $1.38 \mathrm{E}-06$ & 100 & $4.34 \mathrm{E}-07$ & 100 & $7.97 \mathrm{E}-07$ & 100 & $9.46 \mathrm{E}-07$ & - \\
\hline
\end{tabular}

${ }^{\text {a }}$ The absolute difference is the value of difference between the estimated largest and smallest risks in each exposure pathway.

b The relative difference is the value of the absolute difference in each exposure pathway divided by the absolute difference of total risk. 
respectively), the pathways of inhalation of indoor air and shower air are very important. Therefore, although both CalTOX and MMSOILS exclude three pathways, the omissions in CalTOX model does not significantly impact the total risk in this case.

The preceding comparison of modeling results reveals that MMSOILS is improper for the case because it neglects the exposure pathways that are deemed important in the other two models. We can further check that the total risk $\left(1.30 \times 10^{-6}\right)$ in the MMSOILS model is similar to the total risk $\left(1.44 \times 10^{-6}\right)$ in the MEPAS model, if the risk of ingestion of shower water, inhalation of indoor air, and inhalation of shower air is subtracted from MEPAS modeling outputs. Likewise, when the risk of inhalation of indoor air and inhalation of shower air is subtracted from CalTOX modeling outputs, the total risk $\left(1.31 \times 10^{-6}\right)$ in CalTOX model is almost the same as the total risk in the MMSOILS model.

Therefore, MEPAS and CalTOX model are more suitable than MMSOILS in this case. In other words, eliminating unsuitable MMSOILS model can effectively decrease model uncertainty. In this case, the model uncertainty decreases from $2.58 \times 10^{-6}$ to $1.64 \times 10^{-6}$, equaling $36.4 \%$ reduction of model uncertainty.

\subsection{The importance of Monte Carlo simulation}

In contrast to the risk values at 95th percentile calculated in Table 1, Table 3 presents the results of risk values without using Monte Carlo technique to propagate parameter uncertainty. The model uncertainty is $9.46 \times 10^{-7}$ and $38.4 \%$ of the model uncertainty can be reduced. Although the values in Table 3 are all smaller than those in Table 1 and the ranks of the relative difference in Table 3 are the same as those in Table 1, the risk values of four foodchain pathways in CalTOX model become greater than those in the other two models in Table 3, which is due to the smaller parameter uncertainty of foodchain pathways in CalTOX model. Although the selection of better models is not changed in the case, the mentioned outcome obviously reveals that the parameter uncertainty may interfere with selection of better models in other cases.

\subsection{The determination of the major parameters from the better models}

The results from the sensitivity analysis for identifying critical parameters are described in Table 4. It is found that the numbers of important parameters (contribution to variance of total risk greater than $0.5 \%$ ) in MEPAS, MMSOILS, and CalTOX model are 8, 4, 6 respectively. The results show that TCE concentration in groundwater, PCE concentration in groundwater, ingestion rate of drinking water, and body weight are the four important parameters that are identified by

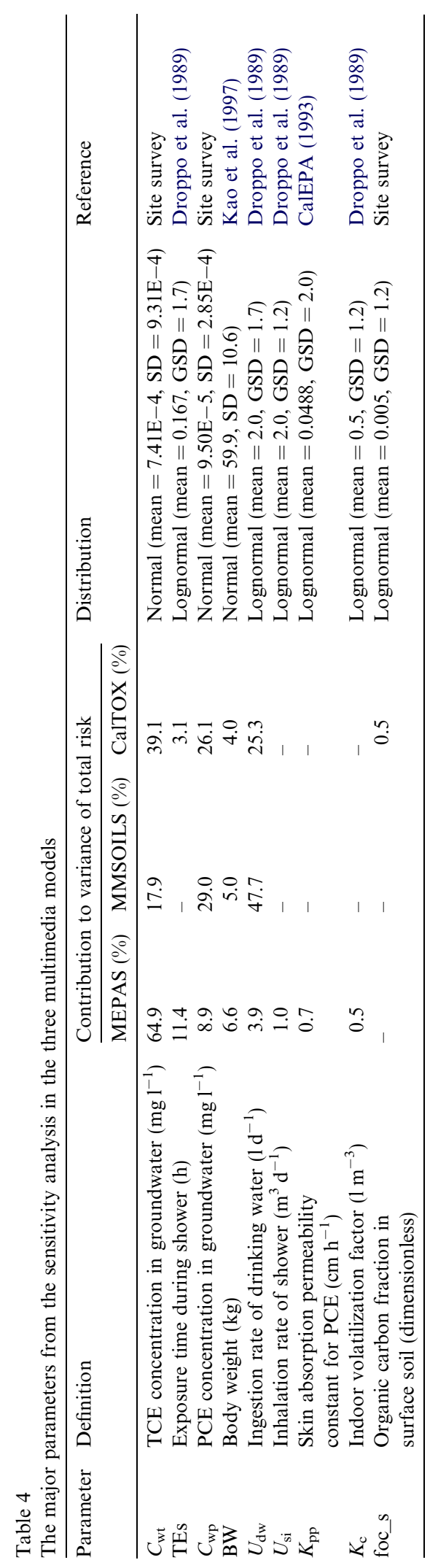


the three models simultaneously, but with different ranks. However, exposure time during shower is an important parameter that is only recognized by MEPAS and CalTOX models. This difference results from the neglect of the important pathway of inhalation of shower air in the MMSOILS model. Therefore, the critical parameters identified by the more suitable models chosen from model comparison are more useful in designing uncertainty reduction measure.

\section{Conclusion}

In the research, three environmental multimedia models combined with conceptual model development and Monte Carlo simulation are applied to a contaminated-groundwater site to demonstrate the processes of model comparison in screening unsuitable models. In the light of significant uncertainty due to model selection, developing such a screening procedure would facilitate uncertainty reduction. Based on the proper model, the identification of important parameters and pathways and design of risk management measures would be better-formed. In this case study, it is found that different consideration of exposure pathways and related mathematical formulations indeed produces different modeling results and that the comparison of the major exposure pathways among models would reveal the suitability of the models. It has also been demonstrated that the model uncertainty is decreased. Furthermore, the sensitivity analysis along with the use of more proper models could facilitate reduction of parameter uncertainty by identifying a better set of important parameters, which may not be considered in an improper model.

Although the results of this particular case study cannot be generalized, the procedure provided in this study can be applied to different cases. The procedure first involves the development of conceptual model for a risk problem. The compatibility of potential candidate models with the conceptual model and comparison of various modeling performance regarding individual exposure pathways are performed by combining Monte Carlo simulation with the models. Then the source of model uncertainty can be identified by checking the model algorithms for the pathways with large contribution to the divergence among models. Finally, the model that neglects the pathways deemed important by most candidate models is considered unsuitable.

Traditionally, executing a model with Monte Carlo simulation can reveal the quantity of parameter uncertainty, but the model uncertainty would not be properly addressed. This procedure of screening models provides a means of reducing model uncertainty. It should also be noted that the parameter uncertainty associated with various models may affect the selection of better models and therefore Monte Carlo analysis needs be used explicitly. The procedure provided in this study is believed to facilitate the reduction of model and parameter uncertainties.

\section{Appendix A. Notations}

$B_{\mathrm{v}}, B_{\mathrm{vi}}$ soil-to-plant concentration factor, $\mathrm{kg}$ soil $\mathrm{kg}^{-1}$ dry plant or $\mathrm{kg}$ dry soil $\mathrm{kg}^{-1}$ wet weight plant

$C_{\mathrm{fvg}}^{\mathrm{abgw}}$ pollutant concentration in above ground vegetables due to irrigation water, $\mathrm{mg} \mathrm{kg}^{-1}$

$C_{\text {as }} \quad$ soil concentration in agricultural field, $\mathrm{mg} \mathrm{kg}^{-1}$

$C_{\text {awi }}$ soil concentration from irrigation water deposition as a function of time, $\mathrm{mg} \mathrm{m}^{-2}$

$C_{\mathrm{dwi}}$ pollutant concentration in domestic water, $\mathrm{mg} 1^{-1}$

$C_{\text {iai }}, C_{\text {ia }}$ pollutant concentration of indoor air outside the bathroom, $\mathrm{mg} \mathrm{m}^{-3}$

$C_{\mathrm{iri}}, C_{\mathrm{irr}}, C_{\mathrm{q}}$ pollutant concentration in irrigation water, $\mathrm{mg} 1^{-1}$

$C_{\text {lvi }} \quad$ leafy vegetable plant concentration at time of consumption, $\mathrm{mg} \mathrm{kg}^{-1}$

$C_{\text {sai }} \quad$ pollutant concentration in shower air, $\mathrm{mg} \mathrm{m}^{-3}$

$\mathrm{CWD}_{\text {lvi }}$ pollutant concentration in leafy vegetables from water deposition onto plants, $\mathrm{mg} \mathrm{kg}^{-1}$

$\mathrm{CWR}_{\mathrm{lvi}}, C_{\mathrm{vu}}$ pollutant concentration in leafy vegetables from root uptake, $\mathrm{mg} \mathrm{kg}^{-1}$

$D_{\text {a }} \quad$ contaminant diffusion coefficient in air, $\mathrm{m}^{2} \mathrm{~s}^{-1}$

$D_{\text {irr }} \quad$ application rate of irrigation, $\mathrm{m} \mathrm{yr}^{-1}$

$D_{1} \quad$ contaminant diffusion coefficient in water, $\mathrm{m}^{2} \mathrm{~s}^{-1}$

$D_{\mathrm{m}} \quad$ mixing depth of soil in agricultural field, $\mathrm{m}$

$\mathrm{DP}_{\mathrm{wi}}$ rate of deposition in irrigation water to cropland soil and plants, $\mathrm{mg} \mathrm{m}^{-2} \mathrm{~d}^{-1}$

$\mathrm{ED}_{k} \quad$ exposure duration for pathway $k, \mathrm{yr}$

$f_{\mathrm{dw}} \quad$ fraction of wet plant remaining as dry material, dimensionless

$\mathrm{FI}_{\mathrm{lv}} \quad$ fraction of year that irrigation occurs for leafy vegetables, dimensionless

$f_{\text {ir }} \quad$ fraction of the pollutant concentration in irrigation water retained in soil water, unitless

$f_{\mathrm{q}}^{\mathrm{w}} \quad$ fraction of water irrigation needs provided by ground water (assumption for 1.0), unitless

$H, H_{i} \quad$ Henry's law constant, $\mathrm{Pa} 1 \mathrm{~mol}^{-1}$ or $\mathrm{m}^{3} \mathrm{~atm} \mathrm{~g}^{-1} \mathrm{~mol}^{-1}$

IR irrigation water application rate during irrigation periods, $1 \mathrm{~m}^{-2}$ month $^{-1}$

$K_{\text {c }} \quad$ Andelman volatilization factor for chemical pollutants, $1 \mathrm{~m}^{-3}$

$K_{\mathrm{D}} \quad$ soil/soil-water partition coefficient, $\mathrm{kg}$ water $\mathrm{kg}^{-1}$ soil solids

$K_{\mathrm{ps}} \quad$ plant-soil partition coefficient from soil to plant parts due to uptake through roots, $\mathrm{kg} \mathrm{kg}^{-1}$ 
$K_{\mathrm{ps}}^{\text {rain }} \quad$ plant-soil partition coefficient for surface soil due to rainsplash, $\mathrm{kg}$ soil $\mathrm{kg}^{-1}$ plant fresh mass

$P \quad$ area soil density of farmland, $\mathrm{kg} \mathrm{m}^{-2}$

$R \quad$ gas law constant, $\mathrm{m}^{3}$ atm $\mathrm{g}^{-1} \mathrm{~mol}^{-1} \mathrm{~K}^{-1}$ or $\mathrm{Pa} 1 \mathrm{~mol}^{-1} \mathrm{~K}^{-1}$

$r_{\mathrm{lv}}$ fraction of deposition retained on plant surfaces, dimensionless

$\mathrm{SAF}_{i} \quad$ soil accumulation factor for an exposure duration of $\mathrm{ED}_{k}$ years, $\mathrm{d}$

$T$ average absolute water temperature in the shower or house, $\mathrm{K}$

$\mathrm{TC}_{\mathrm{lv}}$ duration of the growing period for leafy vegetables, $\mathrm{d}$

$\mathrm{TF}_{i} \quad$ water treatment purification factor, dimensionless

$\mathrm{TF}(\mathrm{q} \rightarrow \mathrm{ep})$ radio of pollutant conc. of exposed produce to the pollutant conc. in groundwater, unitless

$\mathrm{TF}(\mathrm{q} \rightarrow$ inair $)$ radio of pollutant conc. of indoor air to the pollutant conc. in groundwater, unitless

$\mathrm{TH}_{\mathrm{dw}}$ holdup time in transfer from well to the consumer, d

$\mathrm{TH}_{\mathrm{lv}} \quad$ holdup time between harvest of leafy vegetables and consumption by humans, $\mathrm{d}$

$\mathrm{TV}_{\mathrm{lv}} \quad$ translocation factor from plant surfaces to edible parts for leafy vegetables, dimensionless

$\mathrm{UD}_{\mathrm{wi}}$ unit deposition rate to soil, $\mathrm{mg} \mathrm{m}^{-2} \mathrm{~d}^{-1}$

$W_{\text {bath }} \quad$ water use rate for showering, $1 \mathrm{~h}^{-1}$

$W_{\text {house }} \quad$ water use rate for all household activities, $1 \mathrm{~h}^{-1}$

$\mathrm{VR}_{\text {bath }}$ average bathroom ventilation rate, $\mathrm{m}^{3} \mathrm{~h}^{-1}$

$\mathrm{VR}_{\text {house }}$ average house ventilation rate, $\mathrm{m}^{3} \mathrm{~h}^{-1}$

$Y_{\mathrm{lv}} \quad$ yield of leafy vegetables, $\mathrm{kg} \mathrm{m}^{-2}$

$\lambda_{\mathrm{di}} \quad$ environmental degradation and decay constant in surface soil, $\mathrm{d}^{-1}$

$\lambda_{\text {ei }} \quad$ effective weathering and decay constant, $\mathrm{d}^{-1}$

$\lambda_{\text {gi }} \quad$ decay rate constant in closed water system, $\mathrm{d}^{-1}$

$\rho_{\mathrm{b}} \quad$ bulk density, $\mathrm{g} \mathrm{cm}^{-3}$

\section{References}

Andelman, J.B., 1990. Total Exposure to Volatile Organic Chemicals in Portable Water. Lewis Publishers, Boca Raton, FL.

Buck, J.W., Whelan, G., Droppo, J.G., Strenge, K.L., Castleton, K.J., McDonald, J.P., Sato, C., Streile, G.P., 1995. Multimedia Environmental Pollutant Assessment System (MEPAS) Application Guidance, Guidelines for Evaluating MEPAS Input Parameters for version 3.1. Pacific Northwest Laboratory, Richland, Washington.

California EPA, 1993. CalTOX: A Multimedia Total-Exposure Model for Hazardous Waste Sites. Sacramento.

Del Re, A.A.M., Trevisan, M., 1995. Selection criteria of xenobiotic leaching models in soil. Eur. J. Agron. 4, 465472 .
Droppo, J.A., Whelan, G., Buck, J.W., Strenge, D.L., 1989 Supplemental Mathematical Formulations: The Multimedia Environmental Pollutant Assessment System (MEPAS). Pacific Northwest Laboratory, Richland, Washington.

Garen, D., Woodward, D., Geter, F., 1999. A user agency's view of hydrologic, soil erosion and water quality modelling. Catena 37, 277-289.

Hertwich, E.G., Mckone, T.E., Pease, W.S., 2000. A systematic uncertainty analysis of an evaluate fate and exposure model. Risk Anal. 20, 439-454.

Kao, M., Tsan, M., Yeh, W., 1997. Health and obesity of Taiwan citizens. Chin. Nutr. J. 22, 143-171 (in Chinese).

Laniak, G.F., Droppo, J.G., Faillance, E.R., Gnanapragasam, E.K., Mills, W.B., Strenge, D.L., Whelan, G., Yu, C., 1997. An overview of a multimedia benchmarking analysis for three risk assessment models: RESRAD, MMSOILS, and MEPAS. Risk Anal. 17, 203-214.

Lyman, W.J., Reehl, W.F., Rosenblall, D.H., 1982. Handbook of Chemical Property Estimation Methods. McGraw-Hill, Inc., New York.

Ma, H., 2002. Stochastic multimedia risk assessment for a site with contaminated groundwater. Stoch. Environ. Res. Risk Assess. 16, 464-478.

Maxwell, R.M., Kastenberg, W.E., 1999. Stochastic environmental risk analysis: an integrated methodology for predicting cancer risk from contaminated groundwater. Stochastic Environ. Res. Risk Assess. 13, 27-47.

Mckone, T.E., 1993a. CalTOX: A Multimedia Total-Exposure Model for Hazardous Waste Sites: Part I: Executive Summary. Department of Toxic Substances Control, Lawrence Livermore National Laboratory, Livemore, Califormia.

Mckone, T.E., 1993b. CalTOX: A Multimedia Total-Exposure Model for Hazardous Waste Sites: Part II: Multimedia Transport and Transformation Model. Department of Toxic Substances Control, Lawrence Livermore National Laboratory, Livemore, Califormia.

Mckone, T.E., 1993c. CalTOX: A Multimedia Total-Exposure Model for Hazardous Waste Sites: Part III: Multipathway Exposure Model. Department of Toxic Substances Control, Lawrence Livermore National Laboratory, Livemore, Califormia.

Mckone, T.E., Bogen, K.T., 1992. Uncertainty in health-risk assessment: an integrated case study based on tetrachloroethylene in California groundwater. Regul. Toxicol. Pharmacol. 15, 86-103.

Mills, W.B., Cheng, J.J., Droppo, J.G., Faillance, E.R., Gnanapragasam, E.K., Johns, R.A., Laniak, G.F., Lew, C.S., Strenge, D.L., Sutherland, J.F., Whelan, G., Yu, C., 1997. Multimedia benchmarking analysis for three risk assessment models: RESRAD, MMSOILS, and MEPAS. Risk Anal. 17, 187-201.

Moschandreas, D.J., Karuchit, S., 2002. Scenarion-modelparameter: a new method of cumulative risk uncertainty analysis. Environ. Int. 28, 247-261.

National Research Council, 1983. Risk assessment in the Federal Government: managing the process. NAS-NRC Committee on the Institutional Means for Assessment of Risks to Public Health. National Academy Press, Washington, DC. 
Pollock, D., Salama, R., Kookana, R., 2002. A study of atrazine transport through a soil profile on the Gnangara Mound, Western Australia, using LEACHP and Monte Carlo techniques. Aust. J. Soil Res. 40, 455-464.

Regens, J.L., Obenshian, K.R., Travis, C., Whipple, C., 2002. Conceptual site models and multimedia modeling: comparing MEPAS, MMSOILS, and RESRAD. Hum. Ecol. Risk Assess. 8, 391-403.

Taiwan EPA, 2003. Model Validation of Risk Assessment for Toxic Chemicals II. Department of Comprehensive Planning, Taipei, Taiwan (in Chinese).

USEPA, 1989. Risk Assessment Guidance for Superfund: Human Health Evaluation Manual, vol. 1 (Part A). Office of Emergency and Remedial Response, Washington, DC.

USEPA, 1991. Risk Assessment Guidance for Superfund: Human Health Evaluation Manual, vol. 1 (Part B). Office of Emergency and Remedial Response, Washington, DC.

USEPA, 1996. MMSOILS Model: Multimedia Contaminated Fate, Transport, and Exposure Model: Documentation and
User's Manual Version 4.0. Office of Research and Development, Washington, DC.

USEPA, 2002a. TRIM: Total Risk Integrated Methodology: TRIM.FaTE Technical Support Document, vol. I: Description of Module. Office of Air Quality Planning and Standards, Washington, DC.

USEPA, 2002b. TRIM: Total Risk Integrated Methodology: TRIM.FaTE Technical Support Document, vol. II: Description of Chemical Transport and Transformation Algorithms. Office of Air Quality Planning and Standards, Washington, DC.

USEPA, 2003. Multimedia, Multipathway, and Multireceptor Risk Assessment (3MRA) Modeling System, vol. I: Modeling System and Science. Office of Research and Development, and Office of Solid Waste, Washington, DC.

Whelan, G., McDonald, J.P., Gnanapragasam, E.K., Laniak, G.F., Lew, C.S., Mills, W.B., Yu, C., 1999. Benchmarking of the vadose-zone module associated with three risk assessment models: RESRAD, MMSOILS, and MEPAS. Environ. Eng. Sci. 16, 81-91. 